\title{
An endoscopic salvage procedure for the treatment of regurgitation occurring after an unsuccessful esophagectomy with gastric tube reconstruction and subsequent colonic bypass surgery
}

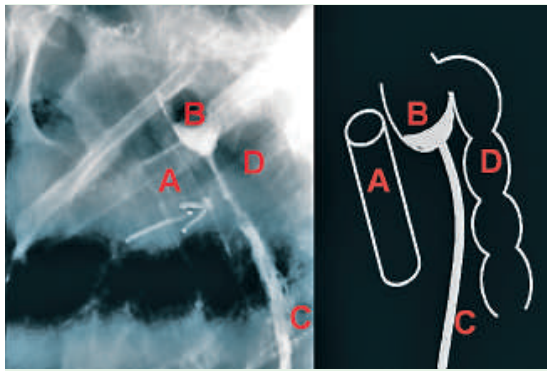

Fig. 1 A water-soluble contrast study and a schematic illustration key showing the gastric tube without filling of the colonic bypass (A, tracheal stent; $B$, esophagus proximal to the stenotic collar anastomosis; $C$, the gastric tube; $\mathrm{D}$, location of the colonic bypass).

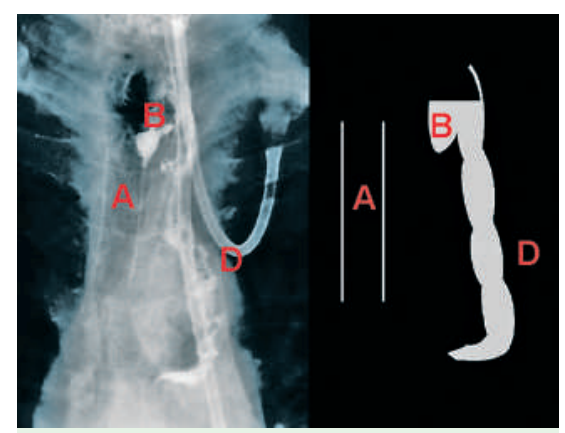

Fig. 3 A water-soluble contrast study and a schematic illustration key showing the appearance after endoscopic de-epithelialization of the stenotic gastric tube and sealing with bucrylate and histoacrylate. An adequate efflux of the contrast medium without filling of the sealed gastric tube was achieved ( $A$, tracheal stent; $B$, esophagus proximal to the stenotic collar anastomosis; D, the colonic bypass).

Anastomotic leaks and strictures after esophagectomy are associated with high morbidity and mortality $[1,2]$. We present here a patient who had a subtotal esophagectomy with gastric interposition because of esophageal adenocarcinoma. Anastomotic leakage occurred and was treated by endoscopic applications of fibrin glue. One month after discharge she presented with a large $(2.5 \mathrm{~cm} \times 5 \mathrm{~cm})$ iatrogenic esophagotracheal fistula. Because of the extensive defect in the pars membranacea and the inflammation we decided against surgical intervention and treated the defect endoscopically using a

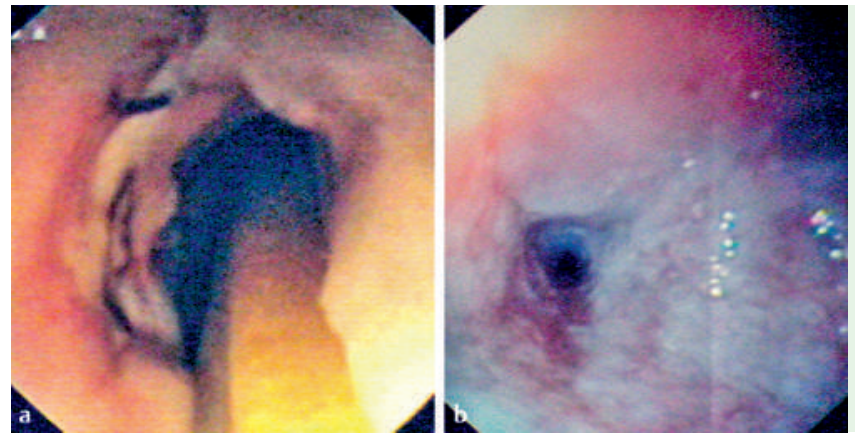

Fig. 2 a Upper gastrointestinal endoscopic image showing a sufficiently wide collar anastomosis of the side-to-side esophagocolostomy. b A stenotic collar anastomosis with a siphon-like anatomical configuration at the entrance to the gastric interposition.

combination of a Vicryl plug and fibrin glue, as described previously [3]. The tracheal fistula was treated with a covered self-expanding tracheal stent [4].

Despite repeated endoscopic dilations, the stenosis recurred due to ischemia. Additional stenting of the anastomotic stenosis was impossible because there was only a thin tissue bridge between the pars membranacea and the (neo-)esophagus and because a stent-to-stent arrangement would most probably have led to further necrosis. The presence of the nasojejunal tube caused considerable psychological stress and impaired the patient's quality of life. To enable her to recommence oral feeding, ascending colonic bypass surgery with collar side-toside esophagocolostomy and intra-abdominal side-to-side colojejunostomy was performed 11 months after the initial operation, leaving the gastric bypass in situ. The endoscopic control showed a wide anastomosis of the esophagocolostomy, but a siphon-like reservoir at the stenotic entrance of the gastric interposition led to regurgitation ( $\bullet$ Fig. 1, 2). We therefore performed an endoscopic closure of the esophagogastric anatomosis, with de-epithelialization of the stenotic gastric tube and sealing with bucrylate and histoacrylate. Control radiography showed adequate efflux without filling of the sealed gastric tube ( $\bullet$ Fig. 3 ). She was able to resume normal oral feeding and her body weight stabilized. This endoscopic approach has not been described in the published literature before. It represents a useful alternative for the treatment of this serious clinical situation.
Endoscopy_UCTN_Code_TTT_1AO_2AI

\section{R. Rosch, S. Truong, M. Jansen, V. Schumpelick}

Department of Surgery, University

Hospital Aachen, Aachen, Germany

\section{References}

1 Urschel JD. Esophagogastrostomy anastomotic leaks complicating esophagectomy: a review. Am J Surg 1995; 169: 634-640

2 Atkins BZ, Shah AS, Hutcheson KA et al. Reducing hospital morbidity and mortality following esophagectomy. Ann Thorac Surg 2004; 78: 1170- 1176

3 Truong S, Bohm G, Klinge $U$ et al. Results after endoscopic treatment of postoperative upper gastrointestinal fistulas and leaks using combined Vicryl plug and fibrin glue. Surg Endosc 2004; 18: 1105 - 1108

4 Chauhan SS, Long JD. Management of tracheoesophageal fistulas in adults. Curr Treat Options Gastroenterol 2004; 7: 31 -40

Bibliography

DOI 10.1055/s-2007-966609

Endoscopy 2007; 39: E270

(c) Georg Thieme Verlag KG Stuttgart · New York . ISSN 0013-726X

Corresponding author

R. Rosch, MD

Department of Surgery

RWTH-Aachen University

Pauwelsstraße 30

52074 Aachen

Germany

Fax: +49-241-80-82417

r.rosch@chir.rwth-aachen.de 